\title{
SENSITIVITY ANALYSIS TO THE COST OF DELAY MODEL FOR NEXTGEN BENEFITS ANALYSIS
}

\author{
Abdul Qadar Kara (Ph.D. Candidate), John Ferguson (Ph.D. Candidate), Karla Hoffman (Ph.D.), Lance \\ Sherry (Ph.D.) \\ George Mason University, Center for Air Transportation Research \\ 4400 University Drive, Fairfax, VA, USA
}

\begin{abstract}
Previous studies of the US Air Transportation System have tried to identify rational airline behavior during times of significant economic and regulatory change [1]. That research indicated that even during periods of increased fuel prices and slot controls at the New York Airports, the airlines chose to reduce the size of the aircraft rather than reduce schedule and increase aircraft size [2]. This study uses delaycost modeling to explain such behavior.
\end{abstract}

This paper extends our previous analysis of airline delay costs [3] by applying that methodology to new data and examining the sensitivity of the results to such data changes. We examine the sensitivity of airline delay costs to aircraft fuel burn rates, fuel prices, crew and maintenance costs, and airline market shares. We observe that delay costs are most sensitive to fuel burn rates. We then identify the aircraft that is "best in class" and find that the current airline behavior of moving to smaller, more efficient aircraft makes good economic sense because it increases frequency while simultaneously reducing the two highest operational costs: fuel costs and crew costs. This finding has significant impact for those responsible for managing congestion in the airspace and at airports.

\section{Introduction}

The airline industry in the United States plays an important role in the US economy. Annually, millions of passengers and tons of cargo are transported by air. Disruptions in air schedules can therefore incur huge losses to the stakeholders involved. These disruptions can be due to delayed or canceled flights and these disruptions propagate throughout the network creating delays and cancelations throughout the day.

Previous studies of the US Air Transportation System have tried to identify rational airline behavior during times of significant economic and regulatory change [1, 4]. Some of these approaches rely on economic feedback, including cost of delay to airlines to predict how alternative control mechanisms might impact the overall throughput of the airline system.

In our previous research [3], we developed a method to calculate the cost of delays during various segments of a flight based on aircraft burn rates, fuel prices and Block Hour Direct Operating Costs (BHDOC). In this paper, we extend our previous work by examining the impact on airline costs when fuel prices and crew costs (the two most significant components of airline operational costs) are changed. We also examine whether alternative aircraft might improve the overall costs for the airlines.

This paper is organized as follows. The next section describes in detail, our cost of delay model. The section after that describes our methodology for testing the sensitivity of the results to changes in costs. We then provide the results of the analysis. 
Finally, we provide our conclusions from this analysis.

\section{Airline Cost of Delay Model}

In our previous study [3], we modified the model presented in the report prepared by the Performance Review Unit, EuroControl in 2004 [5] so that it can be applied to aircraft and flights within the US. The model evaluates costs of delay for each of the different segments of flight (gate delays, taxiout/taxi-in delays, and airborne delays). The model is an additive model that considers fuel burn rates, crew costs, maintenance and other costs (including baggage, ticketing and gating). The cost factors varied based on the length of the delays, where short delays were considered those less than 15 minutes, while long delays were those over 65 minutes.

The additive model derived from [5] has the following parameter values:

$$
\begin{aligned}
& \quad C_{\text {delay }}=c_{\text {fuel }} \times \text { fuel burn rate } \times \text { fuel price } \\
& +c_{\text {crew }} \times \text { crew cost } \\
& +c_{\text {maintenance }} \times \text { maintenance cost } \\
& +c_{\text {other }} \times \text { other cost } \\
& +c_{\text {pax }} \times \text { PAX delay cost } \times(\# \text { seats }) \times \text { load factor }
\end{aligned}
$$

All cost data is in dollars/minute. Table 1 contains the coefficients for each cost component and segment of flight. We note that the coefficients are independent of aircraft type. However, each of these coefficients is multiplied by a corresponding cost that is aircraft dependent. Thus, the model allows one to have delay costs that are aircraft-type specific.
Table 1: Coefficients for Airline Cost of Delay Model

\begin{tabular}{|c|c|c|c|c|c|c|}
\hline \multirow{2}{*}{ Cost Factor } & \multicolumn{2}{|c|}{ Gate } & \multicolumn{2}{c|}{ Taxi } & \multicolumn{2}{c|}{ Airborne } \\
\cline { 2 - 7 } & $\begin{array}{c}15 \\
\text { min }\end{array}$ & $\begin{array}{c}65 \\
\text { min }\end{array}$ & $\begin{array}{c}15 \\
\text { min }\end{array}$ & $\begin{array}{c}65 \\
\text { Min }\end{array}$ & $\begin{array}{c}15 \\
\text { min }\end{array}$ & $\begin{array}{c}65 \\
\text { min }\end{array}$ \\
\hline Fuel & 0 & 0 & 1 & 1 & 1 & 1 \\
\hline Crew & 0 & 0.85 & 0 & 0.85 & 0 & 0.85 \\
\hline Maintenance & 0.02 & 0.05 & 0.02 & 0.05 & 0.02 & 0.05 \\
\hline PAX & 0 & 0 & 0 & 0 & 0 & 0 \\
\hline Other & 0.15 & 0.15 & 0 & 0 & 0 & 0 \\
\hline
\end{tabular}

For delays less than 15 minutes, we use the 15 minutes cost factor; for delays greater than 65 minutes, we use 65 minutes cost factor; for delays between 15 and 65 minutes, we interpolate using two data points. The basis of this modeling effort uses the short and long delays because those are the two categories found in the Euro Control Report upon which our model is based. Figure 1 shows the functional diagram of using this model.

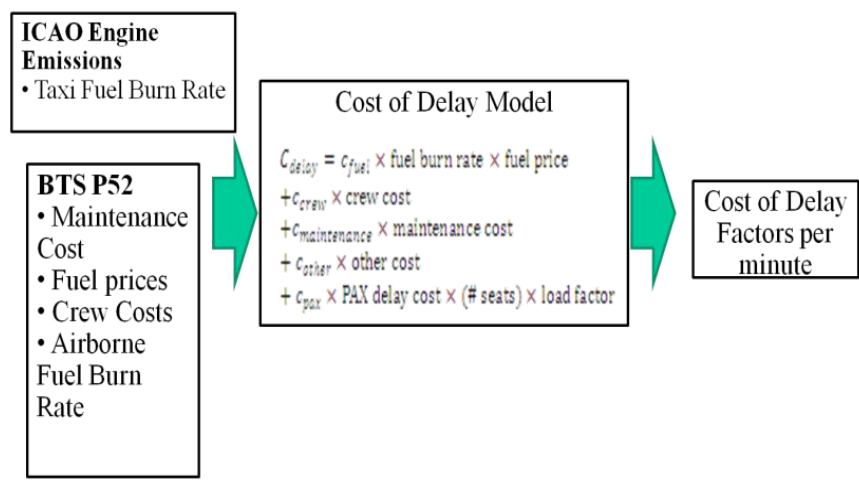

Figure 1: Functional Diagram for Cost of Delay Model 


\section{Methodology}

Fuel and crew costs impact delays since it is these two costs that impact operational costs more than any other costs. We therefore varied these costs and examined how the delay costs incurred by airlines are impacted by variations in these costs. In previous work [2], we saw that airlines have incurred far wider swings in fuel costs between 2005-2009 then any variation seen in crew costs, maintenance costs or other operations costs. Fuel costs have been as low as $\$ 2.50$ per gallon and as high as $\$ 3.50$ per gallon during this time period. In contrast, crew, maintenance and depreciation costs have remained relatively flat. On further examination, we saw significant changes in crew costs during the period 2000-2005, so we will also perform a sensitivity analysis on these costs.

For fuel price changes, we varied per gallon fuel charges from $\$ 1.50$ to $\$ 4.50$ with the base price being $\$ 2.04$ (the average fuel price incurred by the airlines during the Summer 2007). Since no fuel is burned while at the gate, we only examined the taxi and airborne segments of delayed flights. We computed these changes for 30 minutes of delay, since the trends are similar across all delay ranges greater than 15 minutes (due to interpolating the delay cost for ranges between 15 and 65 minutes). We used the BTS P52 database [6] to determine aircraft type for each flight and then used taxi burn rates from ICAO engine emissions databank [7].

For crew costs, we used BTS P52 [6] to determine crew costs per hour by aircraft type for Summer 2007 and varied these costs by decreasing and increasing them as much as $50 \%$. We show a graph for delay above 65 minutes for the given cost ranges and note that, since the crew costs increase linearly, the shape of the graph will remain the same for shorter delays - although the absolute costs will be proportionately less.

We will also examine whether total delay costs as well as overall airborne costs could be significantly decreased had all airlines chosen to use a 'best in class fleet' for flights of given passenger capacity. The concept of 'best in class fleet mix' relates to the selection of an aircraft among fleets of similar sized aircraft that minimize the operating costs to the airline. We acknowledge that the purchase of new aircraft is very expensive and will only occur over time and if the overall long-term costs are minimized. We look at this question of ideal aircraft because it has significant implications for airspace use.

For this paper, we examine costs per delay minute as a metric to optimize. One can then take the data and, for any given flight — or for all flights using aircrafts of a given passenger capacity - compute the overall costs of flight since delay costs are based on three separate segments: airborne, taxiing in/out and time at the gate. From each class, we hand pick the aircraft based on the lowest cost per minute given that it was the right size aircraft for the passenger traffic.

For this analysis, we also consider new aircraft that will become available in the near future. The two new aircraft are the Airbus A380 and the Boeing B787. We note that Airbus A380 is a very large aircraft and not likely to be used for domestic air travel. For these aircrafts, we obtained expected fuel burn rates and seat size based on their documentation. We assumed that crew costs, maintenance costs and other costs would be similar to that of an Airbus A340 for the A380 and that of a Boeing B757 for the B787. 


\section{Results of Analysis}

\section{Sensitivity of Total Delay Costs to Fuel Price Changes:}

Figure 2 compares the percentage change in total cost of delay for airborne and taxi delays. High fuel prices (e.g. $\$ 4.50$ per gallon) result in the total cost of delay increasing by almost $50 \%$ when airborne as compared to a $30 \%$ increase at for taxiing delays.

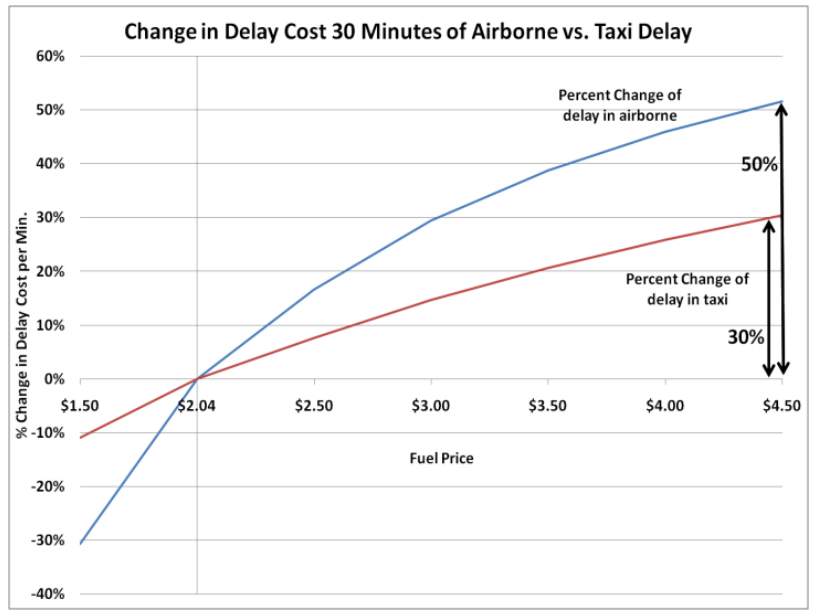

Figure 2: Change in Cost of Delay (30 minutes of Delay) Airborne vs. Taxi Delay

Figure 3 examines how the cost of delay varies with aircraft type during the airborne segment of the trip. All aircraft have the same general relationship to fuel price when graphing the percent change in delay against the change in fuel cost curve. Of course, the absolute change in delay cost as fuel cost increases is dependent of the aircraft type. For a 30minute airborne delay, with a fuel price of $\$ 4.50$ (more than $200 \%$ increase), the delay cost can vary from less than $\$ 13.80$ per minute (for aircraft type E120) to as large as $\$ 304.00$ per minute (for aircraft type B74S, a variant of the B747).

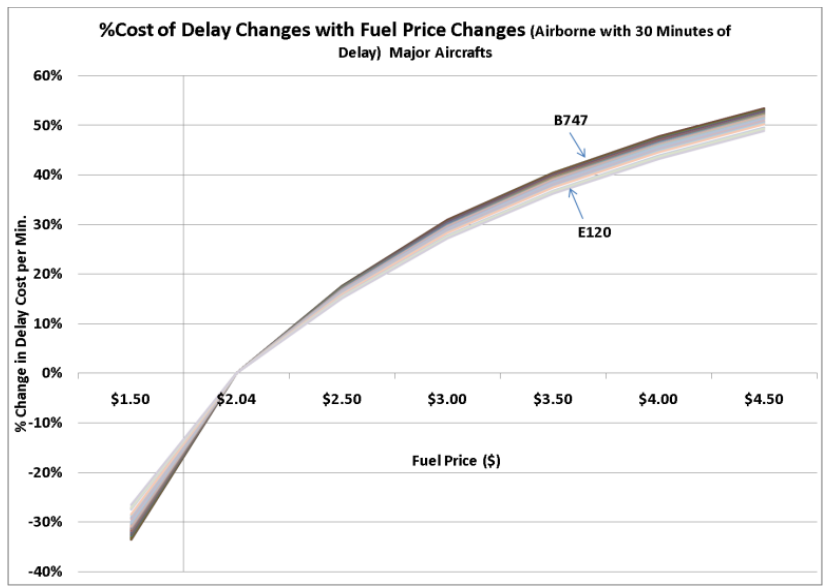

Figure 3: \% Change in Cost of Delay with Fuel Price Change (30 Minutes Airborne Delay) Major Aircrafts

The greatest change in the delay cost is incurred by the aircraft type B74S; with an increase of about $200 \%$ from $\$ 142$ to $\$ 304$, when comparing current prices of approximately $\$ 2.00$ per gallon to a high price of $\$ 4.50$ per gallon.

Similarly when averaging the delay costs of aircraft from a given manufacturer and looking at the delay costs by manufacturer, Figure 4 , we can see the change in cost of delays when fuel price changes from $\$ 1.50$ to $\$ 4.50$. The delay cost, when fuel price is $\$ 4.50$, ranges from a low of $\$ 12$ per minute for Dash's aircraft type to a high of approximately $\$ 143$ per minute for Lockheed aircraft type. 


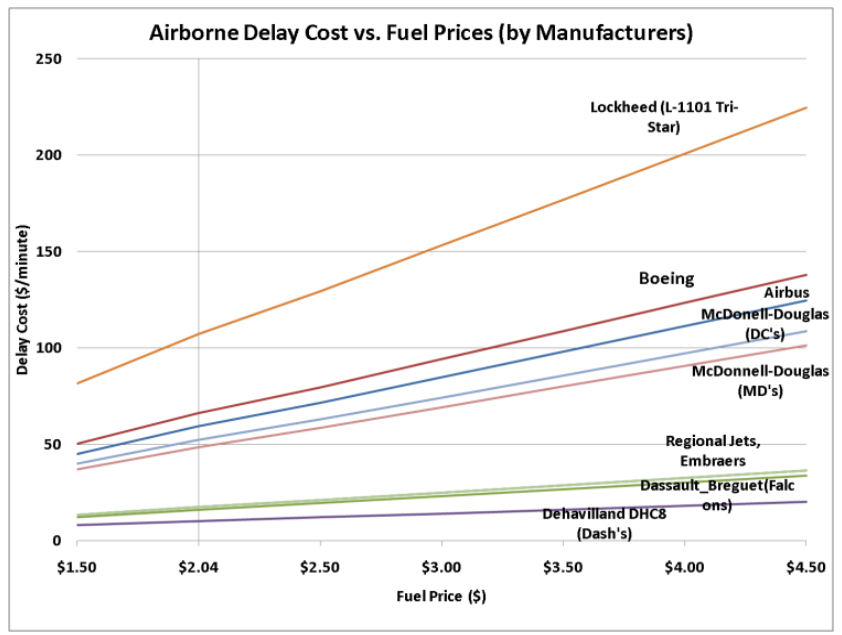

Figure 4: Airborne Delay Cost vs. Fuel Prices (by Manufacturers)

In the US, the approach to handling overcapacity is to try to have as much of the delay take place on the ground rather than in the air. This is accomplished through the Ground Delay Program (GDP) whereby planes are precluded from taking off until there is sufficient airspace and runway availability to assure that the airborne delay is small. Therefore, for any typical delayed flights, longer airborne delays are rare. According to Schumer report [8], in 2007, airborne delays accounted for about $15 \%$ of total delays

Thus, it is the taxing segment of the flight that incurs the majority of the fuel delay cost. For the taxi segment, taxi burn rates are used. These burn rates are approximately $7 \%^{1}$ of the airborne fuel burn rate. This means, that more than fuel price, different fuel burn rates impact the changes in cost of delay.

1 Fuel Burn Rates are derived from BTS P52 [6] and Taxi Burn Rates are derived from ICAO Engine Emissions [7]. The percentage is the difference observed between them.

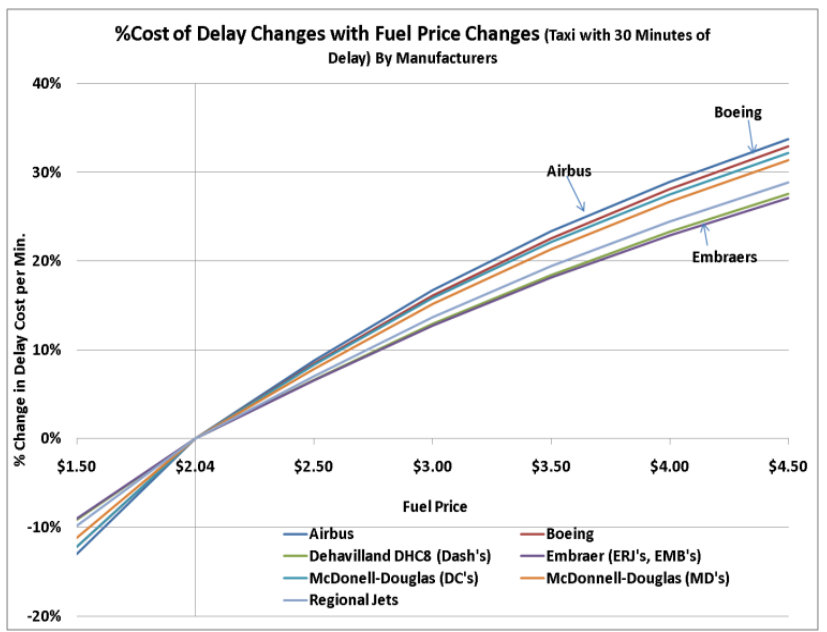

Figure 5: Change in Cost of Delay with Fuel Price Change (30 Minutes Taxi Delay) By Manufacturers

During taxiing we see that aircraft types have more varied effects on delay costs due to significantly different taxi burn rates. Figure 5 shows the percent change in cost of delay with changes in fuel prices for aircraft types grouped by manufacturers. Airbus and Boeing aircrafts are most sensitive to fuel price changes due to their higher fuel consumption. Embraer jets are the most efficient with Dash's and Regional Jets (CRJ's) following them. Table 2 shows the mean and range of percent change in delay cost for 30 minutes of Taxi delay for different aircrafts grouped by manufacturers. Range is defined here as the difference between the maximum and the minimum value.

In the case of the Airbus, the A310 is the most efficient (15\% change in cost of delay) while A346 is least efficient (42\% change in cost of delay at fuel price $\$ 4.50$ ). For Boeing, the range is between $25 \%$ and $40 \%$ change in cost of delay with B737-200 being most efficient to B747 being the least. In the case of Dash's, the DC8 is the most sensitive to fuel price changes; almost 50\% change in cost of delays with fuel price of $\$ 4.50$ while most of the aircraft lie 
between $25 \%$ and $35 \%$ range of percentage change. For regional jets, apart from E110, which is a business jet, and out performs all the others, mostly lie in the $25 \%-35 \%$ range with most aircraft types having less than $30 \%$ change in delay costs.

Table 2: Mean and Range of \% Change in Delay Cost by Manufacturers for different Fuel prices for 30 minute Delay at Taxi

\begin{tabular}{|c|c|c|c|c|c|c|}
\hline \multirow{2}{*}{ Manufacturer } & \multicolumn{5}{|c|}{ Fuel Price } \\
\cline { 2 - 7 } & \multicolumn{2}{|c|}{$\$ 1.50$} & \multicolumn{2}{c|}{$\$ 3.00$} & \multicolumn{2}{c|}{$\$ 4.00$} \\
\cline { 2 - 7 } & Mean & Range & Mean & Range & Mean & Range \\
\hline Airbus & $-13.0 \%$ & $15.0 \%$ & $16.7 \%$ & $15.4 \%$ & $28.9 \%$ & $23.8 \%$ \\
\hline Boeing & $-11.3 \%$ & $13.3 \%$ & $15.1 \%$ & $14.8 \%$ & $26.4 \%$ & $23.6 \%$ \\
\hline $\begin{array}{c}\text { Dash, MD's } \\
\text { and DC"s }\end{array}$ & $-10.9 \%$ & $16.5 \%$ & $14.7 \%$ & $14.8 \%$ & $26.0 \%$ & $21.6 \%$ \\
\hline Regional Jets & $-9.4 \%$ & $8.9 \%$ & $13.2 \%$ & $10.7 \%$ & $23.7 \%$ & $17.5 \%$ \\
\hline
\end{tabular}

\section{Sensitivity of Total Delay Costs to Crew Cost Changes:}

For crew cost changes, we grouped the aircraft by seat size varying the size by 25 seat increments. Figures 6, 7 and 8 show the percentage change in cost of delay for gate, taxiing and airborne delays, respectively, of 65 minute duration.

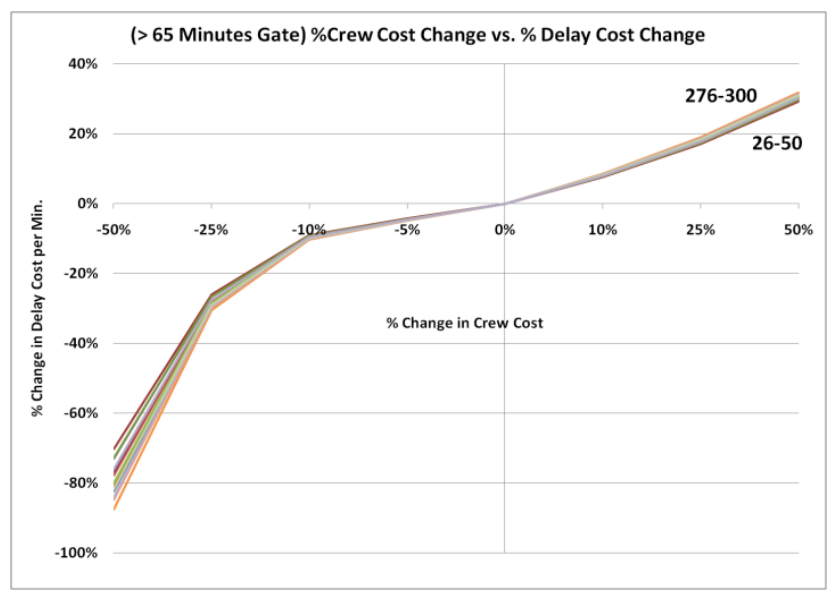

Figure 6: Change in Cost of Delay vs. \% Crew Cost Change (> 65 Minutes Taxi Delay)
For the ground delay segment, since there is no fuel factor involved and crew costs are the major portion of the delay costs, the changes in crew cost incur proportional changes in cost of delay. At 50\% increase in crew costs, the percentage increase in delay costs is around $30 \%$ for all seat sizes. The larger seat size groups of aircrafts tend to be affected more than smaller seat size group, due to their larger crews.

For the taxiing segment, the percentage change in delay costs are less affected by a percentage in crew costs. This is due to the fact, that during this segment, fuel costs dominate the total cost. At a 50\% increase in crew costs, the percentage increase in delay cost is less than $30 \%$.

In the taxi component of delay costs, the larger seat size groups are now less affected by crew costs as compared to smaller seat size group. This is due to the fact, that for larger aircrafts, taxi burn rates are higher, making the total delay cost more sensitive to fuel burn and making the change in delay costs due to changes in crew costs smaller.

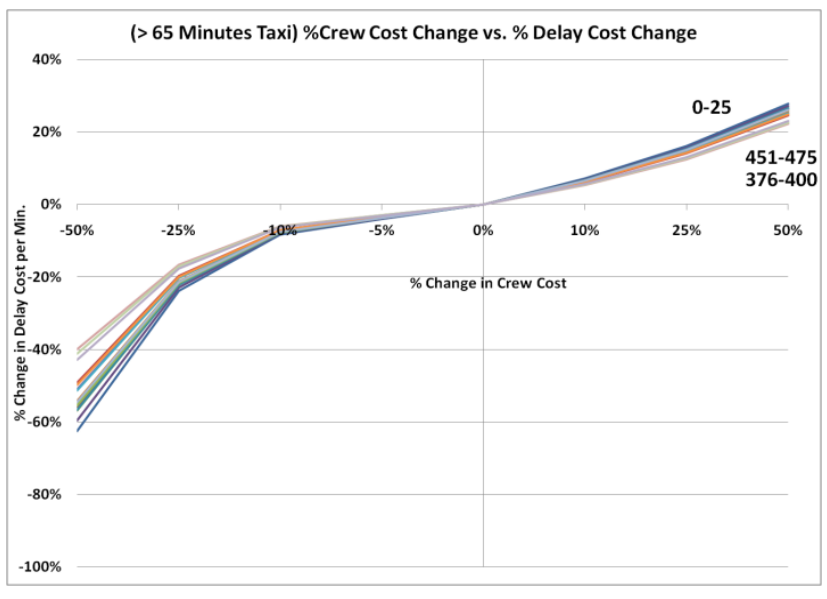

Figure 7: \% Change in Cost of Delay vs. \% Crew Cost Change (> 65 Minutes Taxi Delay) 
For the airborne segment of the trip, the fuel costs are now the major component of delay costs. The difference in percentage change of delay costs for different seat size groups is more visible; larger aircraft are less affected due to their higher fuel burn rates. A $50 \%$ increase in crew costs results in percentage change in delay costs between 3 and $10 \%$.

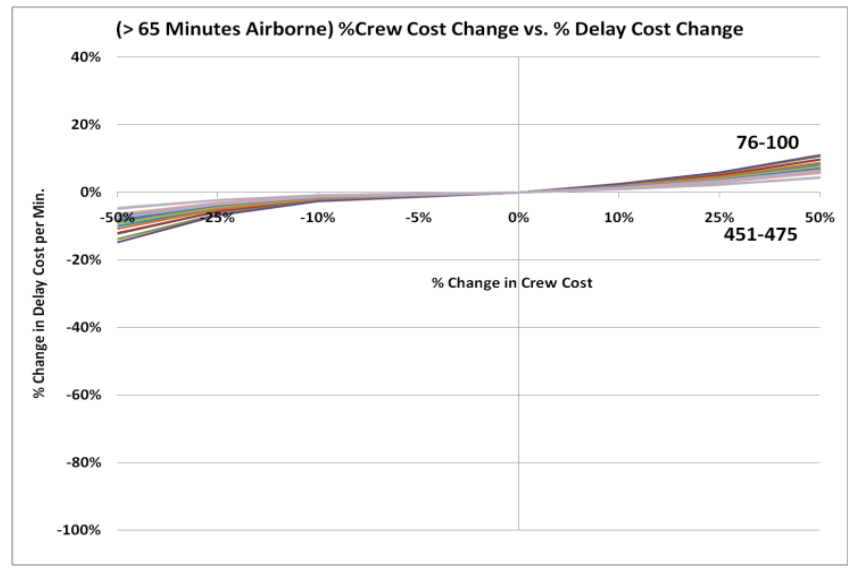

Figure 8: \% Change in Cost of Delay vs. \% Crew Cost Change (> 65 Minutes Airborne Delay)

Best in class analysis of aircraft for specific passenger demand

To determine the best in class fleet mix, as mentioned before, we used 30 minutes of total delay incurred by flights with different aircraft types. This delay was divided into 17 minutes of gate delay, 9 minutes of taxi delay and 4 minutes of airborne delay (The proportion we used is based on delay proportion for Summer 2007 as Philadelphia International Airport or PHL and was also mentioned in Schumer Report [8]). Out of the three metrics used to rank our aircrafts; fuel burn rate was linear in terms of cost of delay per minute, crew cost per minute lie somewhere between linear and exponential (B747 and its variant make it exponential). Since airlines choose aircraft type to use based on market demand, we chose to divide aircraft into seat size categories. Figures 9 through 11 show the charts representing delay cost per minute for a given seat size.

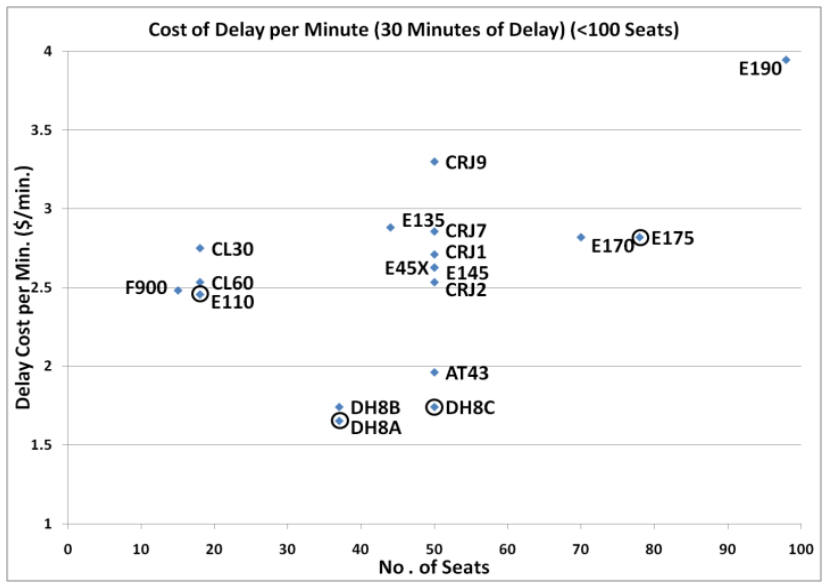

Figure 9: Cost of Delay per minute vs. Seat Size (<100 Seats)

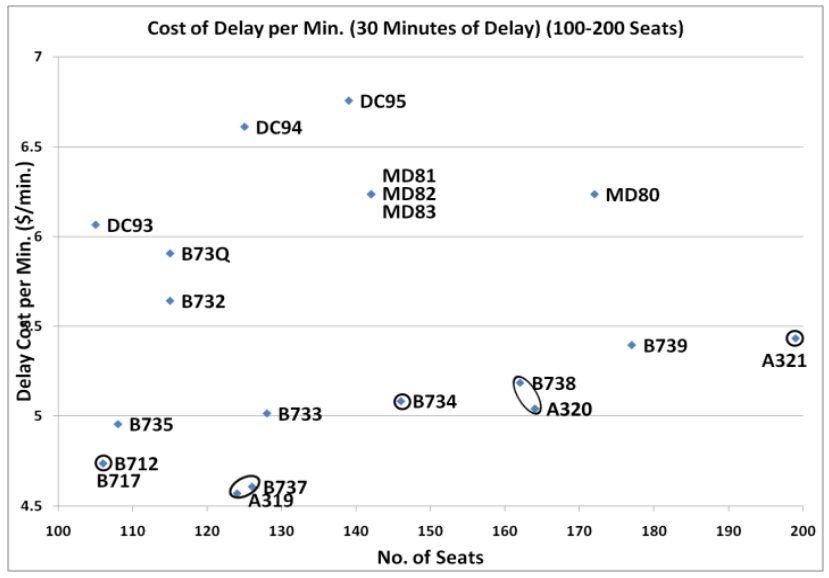

Figure 10: Cost of Delay per minute vs. Seat Size (100- 200 Seats)

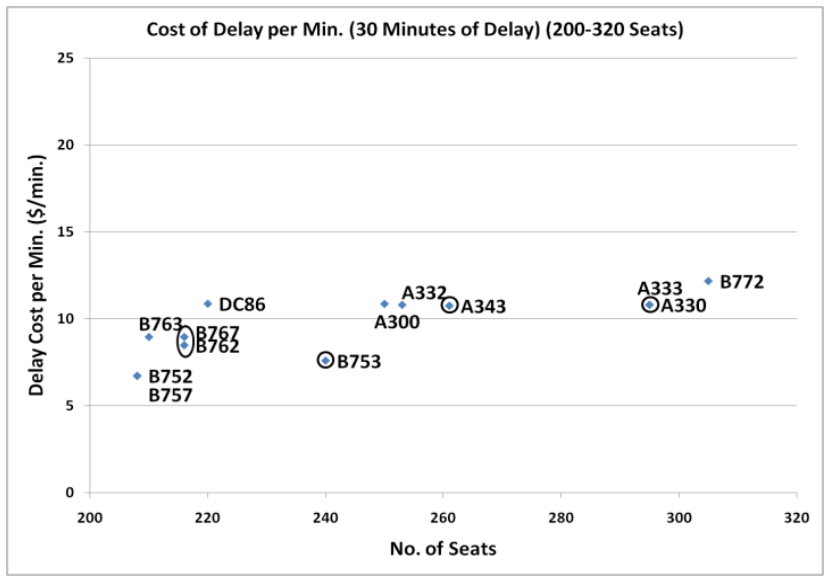

Figure 11: Cost of Delay per minute vs. Seat Size (200-320 Seats) 
The circled points in Figures 9 through 11 show the aircraft that were selected as best in class. For some classes, there were multiple aircrafts that have approximately the same costs for their seat class and so we consider them equivalent.

\section{Table 3 : Best in Class Fleet Mix Selected Based on Cost of Delay per minute vs. Seat Size}

\begin{tabular}{|c|c|c|c|c|}
\hline $\begin{array}{c}\text { Seat } \\
\text { Class }\end{array}$ & $\begin{array}{c}\text { Best in class } \\
\text { aircraft }\end{array}$ & Seat Size & $\begin{array}{c}\text { Fuel burn } \\
\text { rate (per } \\
\text { min). }\end{array}$ & $\begin{array}{c}\text { Crew Cost } \\
\text { (per min). }\end{array}$ \\
\hline$<20$ & E110,CL60 & 18 & $7.47,7.10$ & $3.46,3.57$ \\
\hline $20-40$ & $\begin{array}{c}\text { DH8A, } \\
\text { DH8B }\end{array}$ & 37 & $3.68,3.87$ & $3.36,3.65$ \\
\hline $40-60$ & DH8C & 50 & 3.87 & 3.65 \\
\hline $60-80$ & E175 & 78 & 7.98 & 4.03 \\
\hline $80-106$ & B712, B717 & 106 & 13.78 & 6.51 \\
\hline $106-126$ & A319, B737 & 124,126 & $13.43,13.47$ & $6.07,8.15$ \\
\hline $126-150$ & B734 & 146 & 14.51 & 6.70 \\
\hline $150-170$ & B739, A320 & 177,164 & $16.04,14.45$ & $8.57,5.90$ \\
\hline $170-200$ & A321 & 199 & 16.32 & 4.33 \\
\hline $200-220$ & B762, B767 & 216 & $25.63,27.82$ & 11.38 \\
\hline $220-240$ & B753 & 240 & 23.05 & 7.68 \\
\hline $240-261$ & A343 & 261 & 32.94 & 11.24 \\
\hline $261-295$ & A330, A333 & 295 & 32.94 & 11.24 \\
\hline$>300$ & B744 & 416 & 56.84 & 13.38 \\
\hline
\end{tabular}

Table 3 shows our classes based on seat size and the aircraft chosen for each class. We have not shown aircraft with capacity greater than 320 seats in the above figures since, for that size aircraft, there is only the Boeing B747 that accommodates around 416 passengers.

\section{Performance of New Aircrafts}

Figures 12-14 show the chart representing the cost of delay per minute with seat size, fuel burn rates per minute and crew cost per minute for all aircrafts including A380 and B787 respectively.

In the case of A380, as mentioned before, we used the crew, maintenance and other costs equivalent to the Airbus A340. With respect to fuel burn rates and crew costs per minute, the A340 is more efficient than the Boeing B747 and can accommodate at least 100 more passengers than either variant of the B747. Due to its huge seat size and the inability to land at most of the runways in US, the use of the A340 will be restricted to international flights from a small number of airports.

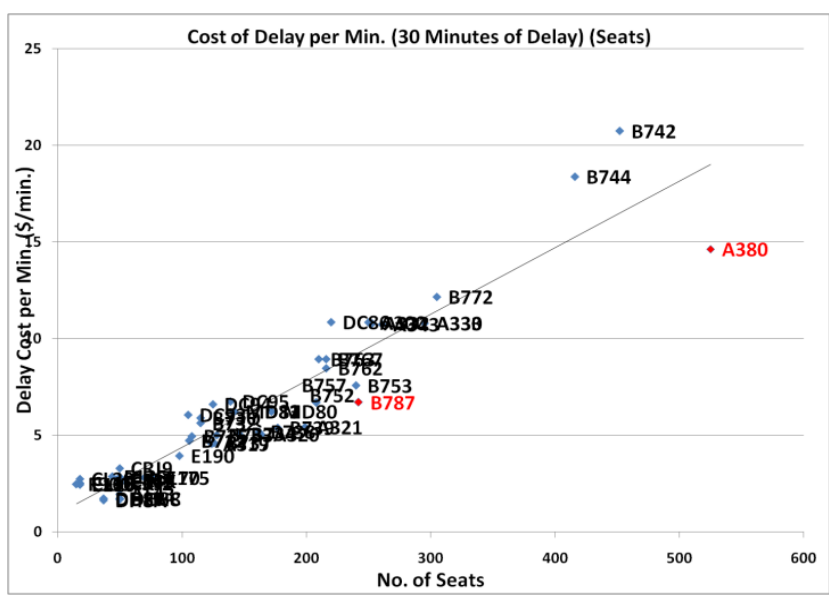

Figure 12: Delay Cost per Minute vs. Seat Size (New Aircrafts in Red)

In the case of the B787, we used the same crew, maintenance and other costs as that for a Boeing B757. According to our defined classes, the B787 will fall between classes 220-240 and 240-260. Altering these classes to 220-242 and 242-260, we can add the B787 into the former class. The B787 is considerably more fuel efficient than the current best aircraft, the B757-3, mainly due to its cheaper crew costs per minute (Fuel burn rates are not significantly different from the B757). 


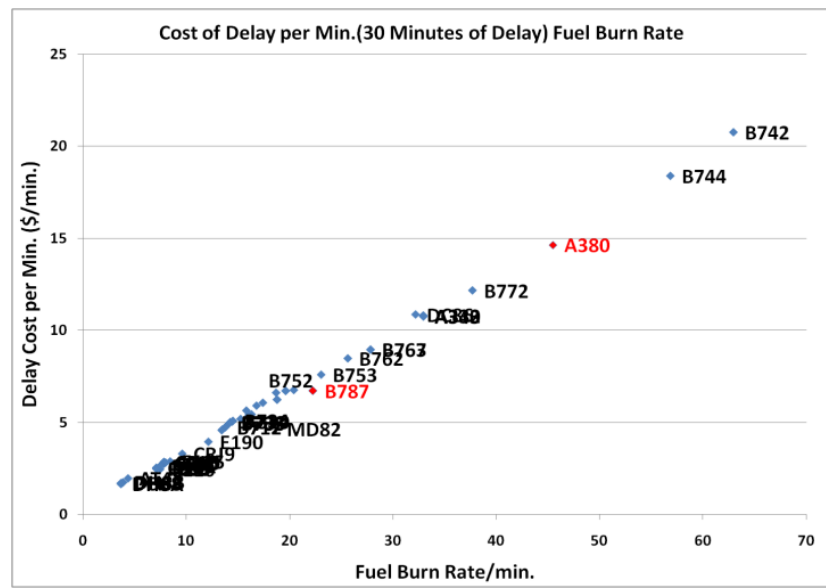

Figure 13: Delay Cost per Minute vs. Fuel Burn Rate (new Aircrafts in Red)

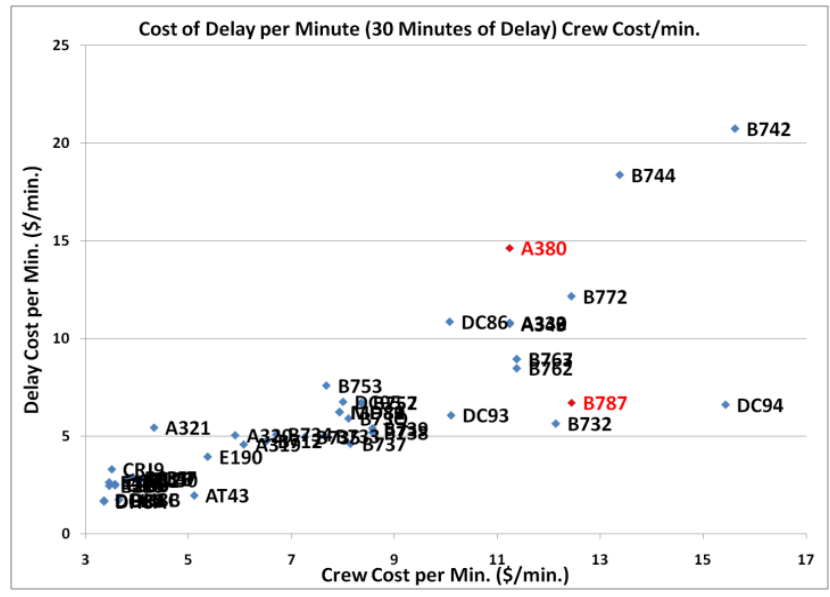

\section{Figure 14: Delay Cost per Minute vs. Crew Cost per Minute (new Aircrafts in Red)}

We also examined exclusively airborne costs rather than delay costs to determine if our conclusions would be different for choice of "best in class" if airborne costs were the determining factor. In no case, did any of the aircraft change when this criterion was used.

\section{Conclusions and Future Work}

From our analysis, we conclude the following:

- From the sensitivity analysis, fuel costs have the greatest impact on delay costs. An increase in fuel price of about $200 \%$ (from \$2.04 to \$4.50) increases the cost of delay by up to $50 \%$ for airborne delays.

- This result is consistent with the current process for handling delays. Namely, the Ground Delay Program (GDP) is designed to have aircraft incur the delays, where possible, at the gate or while in line for takeoff rather than while airborne.

- Since, airborne delays are relatively infrequent (about 13\% of the whole delay incurred by flights in Summer 2007 at PHL); taxi segments of the flight are the ones that create the greatest operational cost to the airline with respect to fuel price changes.

- Fuel burn rates are as important as fuel prices; the same amount of taxi delay in an efficient aircraft can save delay costs by as much as $10 \%$.

- Our analysis has also shown that fuel burn rates for regional jets are better than those for larger aircraft. Thus, by choosing to use smaller regional jets, the airlines save on total operational costs while providing the opportunity to have greater frequency and higher load factors.

- As fuel costs increase, crew costs become far less important to the overall delay and flying costs. For ground delays, crew costs become a larger component of total delay costs, and larger aircraft are impacted since they have larger crews. From our 'best in class' analysis, we calculate that an efficient fleet has the opportunity to reduce the delays costs by $72 \%$ for the scenario of an average delay of 30 minutes for each seat size divided into 17 minutes of ground delay, 9 minutes of taxi delay and 4 minutes of airborne delay. Hence, it is possible to reduce airline delay costs by altering fleet configurations.

- We also examined a 30 minute airborne delay only and operational cost for airborne flight (no delay cost) to see if the best-in-class 
choice would change when only considering airborne delays and airborne costs respectively. This is important since most of the total operational costs of an airline occur during flight. In both these cases, our choice of best-inclass selection remained the same as when considering delay costs.

- Looking at new aircraft about to be introduced, we see that the two new aircraft (the Airbus A380 and the Boeing B787) will not yield significant savings to the airlines at least on their domestic routes. The Airbus A380 will only be used for international routes from selected airports. The Boeing B787, although being a medium sized aircraft, is only slightly better in terms of fuel burn rates.

- Our analysis of delay costs is consistent with current airline behavior. Namely:

(i) Smaller aircraft in the current fleet have better fuel burn rates than the larger aircraft and can be flown with higher load factors (easier to fill a smaller plane), so the airlines are likely to continue to use these aircraft and not up gauge.

(ii) When airlines use smaller aircraft, besides saving on fuel costs, they may also have greater flexibility in repositioning passengers since there are fewer passengers per aircraft.

(iii) Since smaller aircraft have a shorter turnaround time, the airlines might prefer them.

(iv) By using smaller aircraft, an airline can increase frequency to a given market.

We therefore conclude that, as the economy recovers from the current recession, we may expect that the airlines are more likely to increase frequency rather than up-gauging to larger aircraft. Although this approach might not be efficient from an airspaceuse perspective, it makes good economic sense for an airline. If this prediction is correct, we are likely to see resurgence in delays and congestion.

Without the design of new large aircraft that can compete (from an airline operational cost perspective) with the small regional jets currently in use, we cannot expect the airlines to do anything but continue the current trend toward smaller aircraft usage.

\section{Acknowledgements}

We gratefully acknowledge the support and assistance that Michael Bloem, Rosa Oseguera-Lohr and Mike Madson have provided throughout this research effort. This research was partially funded under NASA grant NNX09AB20A and NASA grant NNX07AT23A. We thank George Donohue for his continual encouragement to further understand these cost issues and we thank George Hunter and Huina Gao, both of Sensis Inc, for bringing the EuroControl research and American Airlines study to our attention.

\section{References}

[1] G. L. Donohue, R. D. Shaver III, "Terminal Chaos: Why U.S. Air Travel is Broken and How to Fix It", American Institute of Aeronautics \& Astronautics, Library of Flight, Editor: Ned Allen Spring, 2008.

[2] J. Ferguson, K. Hoffman, L. Sherry, A. Kara , "Effects of Fuel Prices on Air Transportation Performance at New York and San Francisco Airports”, 2009 ICNS Conference, Washington, D.C.

[3] A. Kara, J. Ferguson, K. Hoffman, L. Sherry, "Estimating Domestic U.S. Airline Cost of Delay based on European Model”, Accepted at 4th International Conference on Research in 
Air Transportation - ICRAT 2010, Budapest Hungary June 01 - 04, 2010

[4] M. O. Ball, L. M. Ausubel, F. Berardino, P. Cramton, G. Donohue, M. Hansen, K. L. Hoffman, "Market-Based Alternatives for Managing Congestion at New Yorks LaGuardia Airport, Optimal Use of Scarce Airport Capacity", Proceedings of AirNeth Annual Conference, The Hague, April 2007.

[5] Performance Review Unit, Eurocontrol, "Evaluating the True Cost to Airlines of One Minute of Airborne or Ground Delay," University of Westminster Final Report, May, 2004.
[6] (Online) Bureau of Transportation Statistics (BTS) Databases and Statistics. http://www.transtats.bts.gov/

[7] (Online) ICAO Engine Emissions databank, ICAO Committee on Aviation Environmental Protection (CAEP), hosted on UK Civil Aviation Authority, http://www.caa.co.uk/default.aspx?catid=702 (Updated Feb 2009).

[8] C. E. Schumer, "Flight Delays Cost Passengers, Airlines and the U.S. Economy Billions". A Report by the Joint Committee Majority Staff May 2008.

2010 Integrated Communications Navigation and Surveillance (ICNS) Conference

May 11-13, 2010 